\title{
MACHADO DE ASSIS E "MARIA DUPLESSIS": A TALVEZ PRIMEIRA TRADUÇÃO
}

\section{WILTON JOSÉ MARQUES}

Universidade Federal de São Carlos

São Carlos, São Paulo, Brasil

Resumo: O artigo apresenta a hipótese de "Maria Duplessis", de Alexandre Dumas Filho, ter sido a primeira tradução de Machado de Assis. Além disso, o artigo mostra que, na verdade, a versão machadiana partiu da tradução em prosa de Leonel de Alencar.

Palavras-chave: Machado de Assis; "Maria Duplessis"; tradução; Leonel de Alencar.

\section{MACHADO DE ASSIS AND "MARIA DUPLESSIS": PERHAPS HIS FIRST TRANSLATION}

Abstract: The article presents the hypothesis that "Maria Duplessis," by Alexandre Dumas Filho, was Machado de Assis's first translation. Additionally, the article shows that Machado's version was actually based on the prose translation by Leonel de Alencar.

Keywords: Machado de Assis; "Maria Duplessis"; translation; Leonel de Alencar. 
Hoje, Maria, entre virentes flores

Dormes - em doce e plácido abandono:

Machado de Assis, Maria Duplessis

Se cometi um erro, tenho cúmplices, tue tantos outros, mortos, e ainda vivos. Animaram-me, e bem sabes o que vale uma animação para os infantes da poesia.

Machado de Assis, Posfácio: Carta ao

Dr. Caetano Filgueiras

\begin{abstract}
A partir de 25 de março de 1860, Machado de Assis começou a trabalhar no Diário do Rio de Janeiro, que, depois de breve Linterrupção, voltava a circular naquele mesmo dia, sob o comando
de Saldanha Marinho (DIÁRIO DO RIO DE JANEIRO, 1860a). Para o autor carioca, era o início "oficial" de sua carreira na imprensa, como fez questão de rememorar em famosa crônica: "Nesse ano [1860] entrara eu para a imprensa. [...] Tratava-se do Diário do Rio de Janeiro, que ia reaparecer, sob a direção política de Saldanha Marinho. Vinha dar-me um lugar na redação com ele [Quintino Bocaiúva] e Henrique César Muzzio" (ASSIS, 1994, p. 636). Há apenas vinte dias no novo emprego, Machado publicou, na seção "Variedade", o poema "Maria Duplessis (A dama das camélias) - Imitação de Alexandre Dumas Filho" (ASSIS, 1860, p. 2). Posteriormente, em 1864, o mesmo texto, apenas como "Maria Duplessis" e com modificações pontuais, seria incluído na primeira edição de Crisálidas (ASSIS, 1864, p. 97-100), acompanhado, ao final do livro, pela seguinte nota:
\end{abstract}

Em 1858, eu e o meu finado amigo F. Gonçalves Braga resolvemos fazer uma tradução livre ou paráfrase destes versos de Alexandre Dumas Filho. No dia aprazado apresentamos e confrontamos o nosso trabalho. A tradução dele foi publicada, não me lembro em que jornal. (ASSIS, 1864, p. 170)

Como já bem salientou Jean-Michel Massa, o poeta português Francisco Gonçalves Braga (1836-1860) - mestre e amigo - foi a primeira 
influência poética sobre o jovem Machado de Assis, "um exemplo imitado, copiado e, digamos a palavra certa, plagiado" (MASSA, 2009, p. 111) e, acrescente-se, logo superado. No prefácio de Crisálidas - "O poeta e o livro" , o Dr. Caetano Filgueiras, ao caracterizar o chamado grupo dos cinco, que se reunia com frequência em seu escritório para discutir literatura, não se furtou a afirmar que, entre os assíduos, estava o "inspirado autor das Tentativas [poéticas]" (ASSIS, 1864, p. 7). Entretanto, ainda em Crisálidas, na carta posfácio, em que agradecia as palavras de Filgueiras e ao mesmo tempo trazia para baixo o tom elogioso de suas impressões "parciais e filhas do coração", Machado, ao contrário de reconhecer sua estreia poética em livro "como o resultado de uma vocação superior", como sugeria o advogado, observou a ele e, por tabela, aos eventuais leitores que no cultivo da poesia "se cometi um erro, tenho cúmplices, tu e tantos outros, mortos, e ainda vivos. Animaram-me, e bem sabes o que vale uma animação para os infantes da poesia" (ASSIS, 1864, p. 162-163).

A partir dessas primeiras informações, é deveras curioso perceber que se, na carta posfácio, Machado de Assis relativizou a amizade e a consequente influência literária do "finado amigo", colocando-o na categoria genérica de "tantos outros, mortos", já que Francisco Gonçalves Braga falecera em março de 1860, ${ }^{1}$ na nota sobre "Maria Duplessis", embora reconhecesse de antemão que "resolvemos fazer uma tradução livre ou paráfrase destes versos de Alexandre Dumas Filho", Machado omitiu - ao que tudo indica, de propósito - alguns fatos da história que rondam tanto a fatura do poema de Gonçalves Braga quanto a fatura de sua própria versão. Em outras palavras, é no mínimo suspeito que o poeta brasileiro, ao afirmar que a tradução do amigo fora publicada, mas que "não me lembro em que jornal", tenha omitido que, na verdade, ela saíra em 21 de janeiro de 1856 no próprio Diário do Rio de Janeiro (BRAGA, 1856a, p. 3) e, pouco depois em outubro do mesmo ano, nas Tentativas poéticas (BRAGA, 1856b, p. 283-287), em que há, inclusive, o poema "A um jovem poeta" (O Sr. J. M. M. D'Assis) (BRAGA, 1856b, p. 213-214), que, por sua vez, havia saído antes na Marmota

\footnotetext{
${ }^{1}$ Em 16 de março de 1860, poucos dias depois da morte de Braga no dia 10, o cronista J. Bracarense, na primeira página de A Marmota, escreveu que "Francisco Gonçalves Braga já não pertence ao mundo dos vivos! Qual de nós o dissera, há alguns dias, ao apertar-lhe a mão com a efusão de quem fala a um amigo que nos compreende o coração, que não zomba, mas consola as nossas mágoas! E ele, quem as podia consolar! No vigésimo terceiro ano de vida, o infortúnio não tinha mais fel que lhe dar de beber. Nem assim o mártir abjura a religião, nem assim o peregrino abandonava a senda da glória. [...] Amigos, uma lágrima sobre esta sepultura!" (BRACARENSE, 1860, p. 1).
} 
Fluminense como "Ao Senhor J. M. M. de Assis (em resposta)", em outubro de 1855 (BRAGA, 1855, p. 4). Ainda em relação à nota sobre "Maria Duplessis", é igualmente curioso que, apesar de Braga ter publicado sua tradução em 1856, Machado de Assis tenha situado o momento em que ambos resolveram fazer a "tradução livre ou paráfrase" do poema de Dumas Filho no ano de 1858 e, ao mesmo tempo, não tenha feito qualquer menção à publicação de sua primeira versão no mesmo Diário do Rio de Janeiro, em abril de 1860. Por fim, destaque-se que, quando do aparecimento no jornal, Machado indicou que a sua tradução teria sido feita em 1860, e, quando da republicação em Crisálidas, a mesma foi datada de $1859 .{ }^{2}$ Obviamente, como se depreende, existem vários fios soltos nessa história.

Para começar a juntá-los, é importante relembrar que, como fruto da relação amorosa com o romancista e dramaturgo Alexandre Dumas Filho, Maria Duplessis seria imortalizada na literatura como Marguerite Gautier, protagonista do romance $A$ dama das camélias (1848). Posteriormente, o processo de mitificação da famosa cortesã francesa seria acentuado pelos respectivos sucessos da peça teatral, de mesmo nome, do próprio Dumas Filho em 1852, e - a partir de ano seguinte - da ópera La Traviata, de Giuseppe Verdi, em cujo libreto, adaptado do romance por Francesco Maria Piave, a heroína seria nomeada Violetta Valéry. No entanto, um ano antes do aparecimento do romance, Alexandre Dumas Filho havia publicado o poema "M.D.", que, datado de fevereiro de 1847, fechava o seu livro de poemas Péchés de jeunesse (DUMAS FILS, 1847, p. 389-398). Comentando que a escolha do poema por Machado de Assis tinha "um significado mais sentimental do que literário", Jean-Michel Massa, num breve e severo julgamento da produção poética do romancista francês, afirma que:

Ao retornar da Espanha, Alexandre Dumas Filho visitou o apartamento da célebre odalisca às vésperas da venda de seu mobiliário. Dumas tinha o dom de romancista, um conhecimento de dramaturgo, mas as raras poesias que ele assinou não nos incentivam a celebrá-lo como poeta. Sua meditação, pesada e embaraçada, alongam-se [sic] em estrofes prosaicas. (MASSA, 2008, p. 71)

\footnotetext{
2 Discutindo o problema das datas, Galante de Sousa observa que "sendo diferentes as datas da poesia, na publicação do Diário do Rio de Janeiro e em Crisálidas (1864), preferimos a segunda, porque é de supor que houvesse maior probabilidade de engano no periódico do que no volume de versos, a começar pela revisão, mais cuidada naturalmente neste que naquele" (SOUSA, 1955, p. 334).
} 
Composto o pano de fundo da história, o mistério inicial que cerca a tradução de Machado de Assis, e, acrescente-se, a de Gonçalves Braga, e que provavelmente se desdobrará em outros possíveis mistérios, é o de identificar qual foi a fonte usada pelos autores, o que, diga-se de passagem, sempre trouxe inquietação aos críticos machadianos, seja Galante de Sousa, seja Jean-Michel Massa, para citar dois dos mais representativos. Para o primeiro, Machado de Assis "possivelmente usou mesmo algum volume da edição reduzida de La Dame aux Camelias" (SOUSA, 1955, p. 335); já, para o segundo,

[...] o pior é que não conseguimos encontrar a versão de Dumas utilizada por Machado. [...]. Mas, como três anos antes ${ }^{3}$ F. Gonçalves Braga havia já feito uma tradução [...], não se pode duvidar de que tenha existido uma versão da poesia de Dumas conforme o texto a que Machado de Assis teve acesso. (MASSA, 2008, p. 71, grifo nosso)

Em grande parte, a inquietação dos críticos se devia a um motivo específico, o de, no original de Dumas Filho, existirem 22 estrofes, enquanto, na versão de Braga, há dezessete e, na de Machado, dezesseis. Na verdade, como se mostrará adiante, as duas versões de "Maria Duplessis", de Gonçalves Braga e de Machado de Assis, não partiram do original em francês de Alexandre Dumas Filho, mas sim de outra tradução em português, que, aliás, foi vertida em prosa. No entanto, para desvendar os meandros da história, é preciso antes (re)encontrar a ponta do fio da meada, que, por sua vez, está no próprio Diário do Rio de Janeiro, notadamente no momento em que o jornal começou a ser dirigido por José de Alencar.

\section{O jornal e o fio da meada}

A partir de 6 de outubro de 1855, depois de escrever para o Correio Mercantil entre setembro de 1854 e julho de 1855 e granjear alguma fama literária pelo sucesso de Ao correr da pena, José de Alencar assumiu o cargo de "redator gerente" do Diário do Rio de Janeiro (DIÁRIO DO RIO DE

\footnotetext{
${ }^{3}$ A referência à tradução de Braga como feita "três anos antes" se deve ao fato de Jean-Michel Massa considerar que a versão machadiana era de 1859, ano indicado em Crisálidas.
} 
JANEIRO, 1860b, p. 1). Como era de se esperar, o novo trabalho e as consequentes responsabilidades advindas do cargo eram bem maiores, sobretudo pela necessidade, então, de resgatar a credibilidade do jornal, que atravessava uma fase de agonia e decadência. Nesse sentido, Araripe Júnior afirma que, aos 26 anos de idade, "o moço redator reduplicou de esforços, revelando uma pujança e fecundidade fora do comum". Além de gerenciar o dia a dia do jornal, Alencar também era o responsável pela escrita dos "artigos de fundo, em que tratava dos mais variados assuntos, política em geral, economia política, administração, jurisprudência". Apesar da diversidade temática, os artigos, assevera o crítico, "eram redigidos de improviso e com a verve do publicista consumado" (ARARIPE JÚNIOR, 1958, p. 154).

Apesar da evidente quantidade de trabalho, José de Alencar tentou de todas as formas dar sobrevida à famosa coluna nas páginas do Diário do Rio de Janeiro. Assim, em 7 de outubro, dia seguinte à posse como redator gerente, saía novamente à luz o Ao correr da pena: "Correi, correi de novo, minha boa pena de folhetinista! És livre, como tuas irmãs; abri o voo, lançaivos no espaço. Avante" (ALENCAR, J., 1855a, p. 1). Entretanto, apenas o ímpeto do folhetinista não foi suficiente para levar à frente a empreita, o que fez com que, ao longo daquele final de semestre, a coluna saísse de maneira esparsa. Para ser exato, apenas mais seis vezes, a última, em 25 de novembro de 1855 (ALENCAR, J., 1855b, p. 1; ALENCAR, 1855c, p. 1; ALENCAR, 1855d, p. 1; ALENCAR, 1855e, p. 1; ALENCAR, 1855f, p. 1; ALENCAR, 1855g, p. 1-2). Diante da irregularidade de publicação, José de Alencar, em comunicado oficial na primeira página do jornal, anunciaria então, em 16 de dezembro de 1855, o melancólico fim de Ao correr da pena:

Pedimos desculpa aos nossos leitores pelas faltas que tem havido na publicação da nossa revista hebdomadária. Esta irregularidade porém vai cessar inteiramente.

Um dos nossos redatores que se assina L.a. acha-se incumbido da redação desta revista, que começará a publicar-se regularmente de domingo em diante. (DIÁRIO DO RIO DE JANEIRO, 1855, p. 1)

Como prometido, no domingo seguinte, 23 de dezembro de 1855, o Diário do Rio de Janeiro começou a publicar, no rodapé da primeira página, a nova coluna, batizada apropriadamente de Livro do domingo. No começo do texto, o folhetinista, que se identificava apenas como L.a., mas que, desde 
outubro de 1855 , respondia pela coluna Noites do teatro, apresentou aos seus leitores, como, aliás, era de praxe, o "novo programa" do Livro do domingo:

É a mesma pena que escrevia as Noites do teatro que começa hoje a escrever o Livro do domingo.

Com isso não pretendo apresentar ao leitor uma carta de recomendação; não a tenho: lembro-lhe simplesmente a ocasião em que me viu pela primeira vez.

É pois o mesmo folhetinista de ontem, o folhetinista que vem hoje apresentar aos seus leitores algumas horas de sua vida, dedicadas a eles, o trabalho de um livro ligeiro, o seu Livro do domingo.

Eis quem sou.

[...] Venho substituir ao Correr da pena, e asseguro-vos que a substituição é a mais completa possível.

Primeiro, porque pretendo dar-vos também uma revista ao correr da pena. Neste ponto sobretudo, não deve haver motivo de queixa contra o Diário.

Segundo, porque, se o autor não é o mesmo, é quase o mesmo.

$\mathrm{O}$ autor de ontem assinava-se Al., o de hoje assina-se L.a. Temos apenas uma contradança nas letras, um zigue-zague que deve ser desculpado nesta época de zigue-zagues.

$\mathrm{O} A$ passou da direita para e esquerda, e o $L$ da esquerda para a direita; o ponto (.) que estava no fim passou para o meio.

O A grande sendo substituído pelo a pequeno, havia necessidade que o $l$ fosse escrito em letra maiúscula (L.). [...].

Portanto, vê o leitor que não podia haver substituição mais completa, no caso de necessidade, como houve, de uma substituição de assinaturas.

Aos que não puderem suportar a substituição, e que quiserem iludir-se, vou dar o meio único que encontrei de adoçar-lhes esse mau momento.

Coloquem o Livro do domingo defronte de um espelho, e leiam a assinatura. Contentem-se com a sombra, já que não lhes posso dar mais. Aí fica pois o meu novo programa de folhetinista. Notai que não prometi pouco; está um programa portanto em regra.

E agora, bom dia, meu leitor, como dantes vos dizia boa noite. Conversemos. (ALENCAR, L., 1855a, p. 1)

A mais que evidente intimidade do novo folhetinista com José de Alencar, notadamente quando explicou aos leitores que, por conta de mera "contradança nas letras", a substituição era "a mais completa possível" e que "se o autor não é o mesmo, é quase o mesmo", tem uma razão concreta de ser, já que, na verdade, o autor do Livro do domingo era simplesmente Leonel de 
Alencar, ${ }^{4}$ irmão do redator gerente do Diário do Rio de Janeiro. Identificados o folhetinista e a coluna, é possível então voltar ao problema das traduções de Gonçalves Braga e de Machado de Assis, pois a história delas está relacionada com a estreia no Rio de Janeiro, em 15 de dezembro de 1855, da ópera La Traviata.

\section{A fonte das traduções}

De fato, no acanhado cenário cultural da capital do Império, a expectativa criada pelo público em torno da estreia da nova ópera de Giuseppe Verdi, no Teatro Lírico, foi enorme, tendo sido repercutida à exaustão pela imprensa. Um artigo, sem identificação de autoria, publicado no Correio Mercantil no dia anterior à estreia, dava uma ideia geral sobre o clima de ansiedade que antecedia a grande noite:

Deve subir à cena amanhã no Teatro Lírico a ópera Traviata. É uma das últimas composições de Verdi, e uma das melhores, no conceito dos juízes mais abalizados. [...]. O libreto da Traviata é tirado dos bem conhecidos romance e drama de Alexandre Dumas Filho: A dama das Camélias. [...]. No Rio de Janeiro há muitas pessoas que estiveram em Paris em 1835 e 1836 e que conheceram Maria Duplessis, a heroína que serviu de tipo a Dumas Filho, que a pôs em cena com o nome de Margarida Gautier. O poeta italiano chamou a sua protagonista Violeta

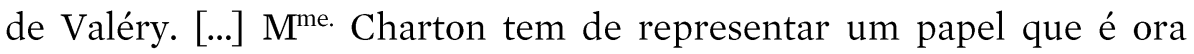
alegre, ora triste, ora leviano, e por fim supremamente dramático e apaixonado. (CORREIO MERCANTIL, 1855, p. 1)

Evidentemente, um acontecimento artístico dessa magnitude não poderia ser ignorado pelo novo folhetinista do Diário do Rio de Janeiro. Tanto que, ainda no primeiro folhetim do Livro de domingo, L.a. não apenas observou que os "entusiastas do teatro lírico têm direito de exigir do folhetinista consciencioso um folhetim que conte a mais bela noite do teatro do Rio de Janeiro", como se apressou em afirmar que "pagarei a minha dívida

\footnotetext{
${ }^{4}$ Corroborando a identidade do folhetinista, Luiz Viana Filho, ao comentar uma crítica à peça Rio de Janeiro Verso e Reverso (1857), de José de Alencar, que fora publicada no próprio Diário do Rio de Janeiro, observa que o folhetinista, sob a sigla "S.F.", dirigia-se ao confrade "L.a.", que, segundo Viana, "não era senão Leonel de Alencar" (VIANA FILHO, 2008, p. 108).
} 
em outro dia" (ALENCAR, L., 1855a, p. 1). E o "pagamento" foi realizado já na semana seguinte, em 30 de dezembro de 1855, sobretudo porque, naquela que, para o folhetinista, tinha sido a "mais bela noite do teatro do Rio de Janeiro", havia outro e maior motivo a incentivá-lo, o papel principal da ópera de Verdi, a cortesã Violetta Valéry, fora representado por ninguém menos que a aclamada $\mathrm{M}^{\mathrm{me}}$. Arsène Charton, musa de quase todos os literatos locais. Como sugere Jean-Michel Massa, "as cantoras [...], com sua auréola de glória, [...], eram bastante requestadas pelos jovens poetas. Ficavam fascinados por elas". No entanto, como a concorrência com os fãs mais abastados era acirrada, "os pupilos das Musas só tinham a oferecer o seu coração" e, obviamente, muitos e muitos versos (MASSA, 2009, p. 121). E, no caso de $\mathrm{M}^{\text {me. }}$ Charton, incluíam-se, entre os seus mais fiéis admiradores, José de Alencar, ${ }^{5}$ Francisco Gonçalves Braga ${ }^{6}$ e o jovem Machado de Assis.

No início do segundo e longo folhetim, que, por falta de espaço na primeira página, fora deslocado para as seguintes, Leonel de Alencar teceu inúmeros elogios ao desempenho artístico de $\mathrm{M}^{\text {me. Charton, corroborados }}$ pelo evidente sucesso de sua atuação em La Traviata. Sem qualquer cerimônia, talvez seja melhor dizer sem qualquer comedimento no uso dos adjetivos, o folhetinista escreveu:

Vou aproveitar do dia em que se dão festas, e em que se pagam todas as promessas, para contar o benefício de $\mathrm{M}^{\mathrm{me}}$. Charton.

São as minhas festas de folhetinista que ofereço às minhas leitoras. Outros vos darão pastilhas, perfumes, pérolas; eu escolhi um assunto cheio de poesia, de beleza e de graça: não troco as minhas festas pelas deles. A voz de $\mathrm{M}^{\mathrm{me}}$. Charton tem mais doçura que a pastilha, tem o perfume da essência de uma flor divina, é uma pérola fluída que nasce n'alma e que brilha no ar com cores mais lindas que as das safiras, das esmeraldas e das opalas.

Fique sabendo desde já que nunca cantora no Rio de Janeiro teve tantos triunfos e tão grande benefício como $\mathrm{M}^{\mathrm{me}}$. Charton nessa noite.

\footnotetext{
${ }^{5}$ Nos folhetins de Ao correr da pena, José de Alencar fez inúmeras referências à $\mathrm{M}^{\text {me. }}$ Charton. Em um deles em especial, datado 28 de janeiro de 1855 e excluído da primeira edição em livro dos textos da coluna, Alencar publicou o poema "Di lei scordarmi!..." dedicado à musa (ALENCAR, 2017, p. 107).

${ }^{6}$ Nas Tentativas poéticas, Francisco Gonçalves Braga publicou nada menos que seis poemas dedicados à $\mathrm{M}^{\text {me. }}$ Charton: uma epístola, uma poesia lírica e quatro sonetos. Inclusive, na organização interna do livro, os poemas à musa antecediam a tradução de "Maria Duplessis" (BRAGA, 1856b).
} 
Além de um colar de 4:000\$ e de uma pulseira de 1:000\$ que eu vi, disseram-me que os admiradores da artista lhe ofereceram 800 ramalhetes de flores. O que asseguro de certo é que ela não apareceu numa só cena que não fosse saudada com entusiasmo frenético e delirante, com palmas que pareciam eternas, bravos em gritos loucos, bouquets lindíssimos, grinaldas as mais delicadas, poesias de diversos autores e retratos de diferentes tamanhos.

Quando no fim do espetáculo ela apareceu no tablado, por três vezes os lencinhos dos camarotes e a alegria que expandia-se nos semblantes das moças, enrubescidas pela emoção e pelo prazer, atestavam que $\mathbf{M}^{\text {me }}$. Charton era uma cantora querida também pelo belo sexo da corte do Rio de Janeiro. (ALENCAR, L., 1855b, p. 2)

Na continuação do folhetim, depois de salientar que os admiradores de $\mathrm{M}^{\mathrm{me}}$. Charton "iluminaram a rua de sua casa, onde uma ceia a esperava, e acompanharam a pé o seu carro com archotes nas portinholas" (ALENCAR, L., 1855b, p. 2), o folhetinista voltou seus olhos ao espetáculo. "Voltemos ao teatro", lembrando aos leitores que "representou-se nessa noite a Traviata de Verdi", para, logo em seguida, indagar-lhes: "sabeis a história da Traviata?". Em resposta à pergunta retórica, chancelou de saída que "é uma história verdadeira, é a vida de Maria Duplessis" (ALENCAR, L., 1855b, p. 2). A partir daí, Leonel de Alencar não apenas escreveu que, para ele, a famosa cortesã "foi mais um anjo de Deus que deixou na terra suas asas brancas, mais uma virgem que perdeu sua cândida grinalda: ela seguiu o seu caminho de transviada" (ALENCAR, L., 1855b, p. 3), como também, para acrescentar detalhes à história da cortesã, traduziu e comentou algumas passagens do artigo "Marie Duplessis ou La Dame aux Camelias", que Alexandre Dumas publicara em seu jornal Le Mousquetaire, em $1^{\circ}$ de abril de 1855 (DUMAS, 1855, p. 193-195). Além de informações factuais, o referido artigo era rematado pela transcrição completa do poema "M.D.", que, como se disse, Dumas Filho fizera à Maria Duplessis. Foi essa mesma versão do poema que Leonel de Alencar traduziu em prosa no seu Livro do domingo. ${ }^{7}$

Entretanto, ao contrário das 22 estrofes do poema original, o irmão de José de Alencar, não se sabe o porquê, optou pela tradução de apenas dezessete. Aliás, não somente deixou de traduzir cinco estrofes $(1,11,12,21 \mathrm{e}$ 22), como também inverteu a ordem natural das estrofes 8 e 9 , que, por conta

\footnotetext{
${ }^{7}$ Para o poema de Alexandre Dumas Filho, publicado em Le Mousquetaire, ver: Anexo 1.
} 
das exclusões, tornaram-se 7 e 8 em sua tradução. O que, longe de intencional, talvez possa ter ocorrido por algum erro de composição tipográfica do jornal, já que a inversão em si não impacta de modo significativo a compreensão do próprio texto. De toda forma, antes mesmo de apresentar o poema em que, para ele, "estava a história inteira de Maria Duplessis" (ALENCAR, L., 1855b, p. 3), o folhetinista ainda fez questão de informar aos seus leitores que, de fato, era o autor daquela tradução: "aí vão eles traduzidos por mim à pressa, como [Émile] Souvestre traduziu alguns versos de Byron, metrificando a prosa" (ALENCAR, L., 1855b, p. 3, grifo nosso). Veja-se a tradução de Alencar:

Tinha-te escrito que voltaria um dia para pedir-te perdão. - Eu julgava dever a minha primeira visita à minha última afeição.

E quando corria para abraçar-te depois de tanto tempo de ausência, encontrei tua casa fechada. - E vieram dizer-me que uma sepultura recente fechava para sempre tua fronte adorada.

Contaram-me friamente que depois de longo sofrimento a enfermidade tocou o ponto forte. - E a fatalidade lançou com ironia a minha esperança ainda viva à notícia de tua morte.

Tornei a ver subjugado por tristes pensamentos a escada e o assoalho que pisara tão contente.

$\mathrm{E}$ as paredes, que, confidentes das coisas desfeitas, para falar do morto esbarram o vivente.

Subi, tornei a abrir essa porta, chorando, que um dia ambos chorando abrimos tão infelizes...

E em minhas saudades evoquei, morta querida, o fantasma nublado de nossos dias felizes.

Assentei-me a essa mesa onde vínhamos cear nas noites de verão. - E tudo ainda falava do nosso amor descuidoso a meu triste coração.

Entrei em teu boudoir, meu oásis divino, onde ainda brilhavam suas lindíssimas cores. - Revi teus quadros e teus vasos da China onde ainda morriam alguns ramos de flores. 
Vi o piano de que acordavas para mim lindos concertos e que deixaste aberto. - Tua morte deixou-o frio e vazio, como o estio partindo deixa o arbusto deserto.

Tornei a encontrar teu quarto doce e sombrio, e lá a saudade velava pungente e sagrada. Um raio iluminava tua cama recostada na sombra, mas já não dormias nessa cama adorada.

Abri os cortinados de cetim cor de rosa, que amparavam de manhã a luz amortecida. - Permitindo somente que um raio depusesse um toque de alegria em tua fronte adormecida.

Era aí que outrora linda sombra perdida, vivíamos ambos depois da meia-noite. - E até raiar o sol do outro dia, ouvíamos passar as horas da noite.

Então olhavas, banhada de luz, o fogo como a serpente na lareira correr: - porque o sono fugia de teus olhos tão lindos, e tu já sofrias do que te fez morrer.

Recordas-te ainda no mundo em que estás das coisas da terra e do seu misérrimo gozo? - Ouves passar por seu túmulo o cortejo de festas em que buscavas repouso?

Recordas-te das noites em que ardente e amorosa torcias aos meus beijos teu corpo voluptuoso? - E fatigada encontravas o sono, consumida e trêmula na febre do gozo?

Como o verme que rói uma flor que emurchece, a insônia constante derrotava-te as cores. - E fazia de ti a cortesã sempre pronta a todas as festas e a todos os amores.

E agora Maria tu gozas, entre as flores, sem temor de acordar, o repouso desejado; - Deus soprou tua alma emurchecida, e pagou-te de uma vez o sono retardado.

Pobre mulher! Em tua última hora, só um homem assistiu ao teu derradeiro momento. - E somente dois amigos de teus amigos de outrora, levaram ao cemitério o teu saimento. (ALENCAR, L., 1855b, p. 3) 


\section{Gonçalves Braga \& Machado de Assis: a ordenação dos fios}

Em fins de 1855 e inícios de 1856, Francisco Goncalves Braga tinha dezenove anos e Machado de Assis, dezesseis, o que pode sugerir que, naquele momento, ambos ainda não tinham o completo domínio da língua francesa. Aliás, nesse sentido, no elogio fúnebre a Braga, feito por J. Bracarense na primeira página de $A$ Marmota em 16 de março de 1860, o cronista, entre outros aspectos biográficos, destaca a relação do jovem português com a língua francesa, afirmando que "não há muito que ignorava os rudimentos da língua de Hugo e de Lamartine, e hoje era versadíssimo nas páginas imorredouras, da águia e do cisne da poesia francesa" (BRACARENSE, 1860 p. 1).

A despeito da imprecisão temporal por trás do "não há muito" do cronista de A Marmota, a afirmação sobre Braga pode muito bem ser estendida ao jovem Machado de Assis. Como explica Jean-Michel Massa, o autor brasileiro "começou a traduzir em 1857, e sua atividade nesse campo continuou até 1894". Sua primeira tradução teria sido $A$ ópera das janelas, em agosto de 1857, mas, complementa o crítico francês, "não se conhece essa opereta exceto pelo parecer emitido pela comissão de censura do Conservatório" (MASSA, 2008, p. 18-19). Pouco depois, entre setembro e dezembro de 1857, Machado publicou, inicialmente na Marmota Fluminense e, em seguida, em A Marmota, alguns capítulos da História da Restauração, de Lamartine, sob o título "A literatura durante a restauração" (ASSIS, 1857a, p. 1; ASSIS, 1857b, p. 1; ASSIS, 1857c, p. 3; ASSIS, 1857d, p. 4; ASSIS, 1857e, p. 1-2; ASSIS, 1857f, p. 3-4; ASSIS, 1857g, p. 2-3). Por fim, para ficar apenas nas traduções iniciais, o primeiro poema traduzido e publicado por Machado de Assis foi "A uma donzela árabe", do mesmo Lamartine, e que somente sairia em 20 de janeiro de 1859 no jornal O Paraíba (ASSIS, 1859a, p. 3).

Pois bem, para começar então a ordenar os fios da história, é possível afirmar de saída que as traduções de Francisco Gonçalves Braga e de Machado de Assis foram, na verdade, meros exercícios literários, ou seja, os jovens poetas apenas e tão somente colocaram em versos a tradução em prosa de Leonel de Alencar. O que, por exemplo, explicaria a "meia verdade" da nota sobre "Maria Duplessis" em Crisálidas, quando Machado afirmou que "Em 1858, eu e o meu finado amigo F. Gonçalves Braga resolvemos fazer uma tradução livre ou paráfrase destes versos de Alexandre Dumas Filho. No dia aprazado apresentamos e confrontamos o nosso trabalho" (ASSIS, 1864, p. 170. Ou seja, ao que tudo sugere, o ano em que, na verdade, "resolvemos 
fazer" tanto a "tradução livre ou paráfrase" quanto o confronto do "nosso trabalho" foi 1856, e não 1858, e o "dia aprazado" foi provavelmente em algum momento do mês de janeiro do mesmo ano. Já que, embora Machado de Assis tenha afirmado que "A tradução dele foi publicada, não me lembro em que jornal"(ASSIS, 1864, p. 170, grifo nosso), Gonçalves Braga, como já se disse, publicou-a no Diário do Rio de Janeiro em 21 de janeiro de 1856 . Vejase a tradução de Braga, "Maria Duplessis (A transviada) - Por A. Dumas Filho":

Escrevi-te, a dizer-te que algum dia Voltaria a pedir-te o meu perdão:

Eu julgava dever minha visita

Primeira à minha última afeição.

E quando após a ausência ia abraçar-te, Somente a tua casa eu vi fechada, E disseram-me então que a sepultura Guardava tua fronte idolatrada!

Relataram-me então com indiferença Que o teu mal se elevou ao grau mais forte;

Matou com ironia a desventura

Minha esperança, inda viva, com tua morte!

Tornei a ver no triste pensamento

Teu quarto, que eu já vira tão contente, $\mathrm{E}$ as tristes paredes que ficaram

P'ra falar do bem morto ao bem vivente!

Subi a escada - abri, chorando, a porta

Que outr'ra nós abrimos infelizes;

Evoquei na saudade a tua imagem, Lembrando os nossos dias mais felizes!

Assentei-me na mesa em que sozinhos Ceávamos nas noites de verão; Ali do nosso amor tudo falava

Ao meu dilacerado coração!

Entrei no teu formoso camarim 
Ornado ainda de brilhantes cores, Vi teus quadros, teus vasos do Oriente, Onde estavam morrendo algumas flores!

O piano inda vi, do qual me davas Suaves notas, e o deixaste aberto; Tua morte o deixou calado e triste Como o estio o arbusto, - só, deserto!

Tornei a ver teu quarto, onde velava A saudade pungente e mais sagrada; Um raio dava luz sobre o teu leito, Já nele não te vi, de amor deitada!

Abri seus cortinados cor de rosa, Que amparavam a luz amortecida, Permitindo somente que alegrassem Seus raios tua fronte adormecida!

Era aí, noutro tempo, que ambos juntos Vivíamos depois da meia noite, Ao ouvir, até raiar o sol do dia, As horas a bater do tempo açoite!

Então me olhavas tu, pálida, ardente, Qual serpente no fogo, inda a correr; Fugia o sono de teus olhos belos; Era a moléstia que te fez morrer!

Acaso te recordas nesse mundo Das coisas deste, de amargado gozo? Ouves passar na laje do teu túmulo Cortejo do festim, que era enganoso?

Recordas-te da noite em que meus beijos Fugias com teu corpo voluptuoso, E cansada de amor, já vinha o sono Cerrar teus olhos, tão febris de gozo?

Qual um verme que rói a flor que murcha, Constante insônia te apagava as cores; Tu sofrias, mas sempre preparada 
Para todas as festas e amores!

E agora, Maria, entre mil rosas

$\mathrm{Tu}$ gozas do repouso desejado,

Sem temor de acordar, que Deus pagou-te

De uma vez o teu sono retardado.

Pobre mulher! Na extrema hora da vida

Um homem viu teu último momento,

Dois amigos d'amigos teus de outr'ora

Conduziram teu fúnebre saimento! (BRAGA, 1856a, p. 3)

De imediato, salta aos olhos o fato de Gonçalves Braga ter usado, como subtítulo ao poema, a expressão "a transviada", a mesma, diga-se de passagem, que Leonel de Alencar usou no folhetim quando escreveu que a cortesã "[...] seguiu o seu caminho de transviada" (ALENCAR, L., 1855b, p. 3), fazendo com que, dessa forma, poema e folhetim remetam, de modo algo previsível, sonora e semanticamente ao título da ópera de Verdi, La traviata.

Quanto à tradução em si, o rápido cotejo com a versão de Leonel de Alencar revela vários dados interessantes que atestam (e muito) a proximidade de ambas. De início, para ficar em três exemplos de natureza formal, é importante salientar que Braga organizou estruturalmente a sua versão em quadras, com versos decassilábicos e com rimas apenas nos pares. Além disso, o número de estrofes é rigorosamente igual ao de parágrafos, ou seja, dezessete, e, por fim, Braga manteve a mesma inversão das estrofes 7 e 8 da versão de Alencar, o que obviamente indica que ele não partiu do original francês. Ainda que se leve em conta que, no caso do poeta português, há o atenuante do problema da exigência métrica, quando se faz a comparação direta entre a primeira estrofe e o primeiro parágrafo da versão em prosa do folhetinista, as semelhanças, para não dizer gritantes, são bem visíveis. Vejam-se os textos:

Tinha-te escrito que voltaria um dia para pedir-te perdão. - Eu julgava dever a minha primeira visita à minha última afeição. (ALENCAR, L., 1855 b, p. 3, grifo nosso)

Escrevi-te, a dizer-te que algum dia

Voltaria a pedir-te o meu perdão:

Eu julgava dever minha visita

Primeira à minha última afeição. (BRAGA, 1856a, p. 3, grifo nosso) 
Além das evidentes modificações nos dois primeiros versos, Gonçalves Braga, quase ipsis litteris, incorpora aos versos finais da primeira estrofe os mesmíssimos termos da tradução em prosa, apenas com o trabalho de, por razões da métrica, eliminar o "a" de "a minha primeira visita" e o de inverter a ordem das palavras para: "minha visita / Primeira". Se se continuar cotejando os textos, verificar-se-á que o padrão composicional se repete, em maior ou menor grau, em praticamente todo o corpo do poema.

Para não pairar qualquer dúvida sobre o fato de a tradução de Leonel Alencar ter sido a fonte do poeta português e, ao mesmo tempo, para também salientar que provavelmente foi mesmo em 1856, e não em 1858, que ele e Machado começaram a trabalhar nas respectivas traduções dos versos de Dumas Filho, basta reproduzir dois detalhes sutis da versão de Braga, impressos ao final do poema, "Metrificado por F. Gonçalves Braga" e "Corte, 31 de dezembro de 1855" (BRAGA, 1856a, p. 3). Ou seja, a versão do português foi escrita no dia seguinte à publicação da tradução de Leonel de Alencar no Diário do Rio de Janeiro, o que, por sua vez, e pela evidente pressa na construção da fatura poética, explicita não apenas a óbvia similitude entre os textos, como também sugere o momento inicial em que os jovens poetas resolveram fazer suas traduções.

Entretanto, se, por um lado, no confronto dos trabalhos, Francisco Gonçalves Braga venceu momentaneamente, já que publicou sua versão, por outro, o jovem Machado de Assis não saiu de todo derrotado da contenda poética. Exatos dezessete dias depois de sair o poema de Braga, Machado talvez como prêmio de consolação - também fez jus ao direito de publicar no mesmo Diário do Rio de Janeiro, aliás, publicava pela primeira vez na grande imprensa. Embora sua tradução ficasse para mais tarde, ao menos em 7 de fevereiro de 1856 e com a provável anuência (e quem sabe até com o incentivo) do também chartonista José de Alencar, Machado publicou um longo poema em homenagem à cantora, que, para desgosto dos admiradores, anunciara estar de partida para a Europa. ${ }^{8}$ Ainda muito contaminado pelos

\footnotetext{
${ }^{8}$ Em 16 de março de 1856, no mesmo dia em que Charton viajou para a Europa, o folhetinista do Livro do Domingo tentou consolar os "órfãos" da cantora. Para ele, "M ${ }^{\text {me. }}$ Charton será sempre para o Rio de Janeiro uma dessas tradições que não se escrevem e que se guardam como uma lenda. Haveis de ouvila sempre que ouvirdes uma bela flauta tocar um pedaço da Traviata ou do Trovador; e a doçura quase
} 
ecos recentes de La Traviata, o jovem vate, em "À Madame Arsène Charton Demeur", expressou a sua mais completa idolatria pela musa, que era nada menos que "o sol" que iluminava "o céu das artes" e que, por isso mesmo, o moço poeta era o "Que mais que todos te admira o canto". Veja-se, nesse sentido, alguns fragmentos do poema:

Heroína da cena, que entre as flores

Que a senda esmaltam da carreira d'arte,

Em que orgulhosa pisas, ostentando

A fronte além das sombras que forcejam

Debalde por calcar teu nome e glória,

Colhes coroas mil com que te adornas,

Benévola me escuta. Eu sou bem fraco,

Mas poeta me creio, se o teu nome

Na lira acordo que meu peito exalta!

Que vai o templo, se lhe falta o nume?

Não nos fujas daqui, Charton divina!

Deserto fica o majestoso alcáçar

Que Verdi exalta com florões de glória!

[...]

Da tua bela voz ermo de influxos,

Repercutindo apenas dentro d'alma

Os ecos de teu canto sonoroso,

A cada som pungindo uma saudade!

Oh sol que o céu das artes iluminas,

É cedo o ocaso teu na nossa terra!

$[\ldots]$

$[\ldots]$

Musa gentil dos versos que ora teço, Quando longe de nós, lá n'outro palco, Traduzindo as de Verdi obras sublimes, Outros mortais que anelam ver teu rosto E ouvir teu canto cheio d'harmonias.

Com meiga e doce voz extasiares,

divina de sua voz argumentará aos ouvidos que a ouviram, a suavidade da melodia dessas músicas" (ALENCAR, 1860, p. 1). 
Recorda o canto meu, - recorda o vate

Que mais que todos te admira o canto,

Talento e garbo que ostentas na cena!

Não mais minh'harpa! - Inda uma vez te peço,

Não nos fujas daqui - Charton divina!

$[\ldots]$

Grande, eterno,

Refulge o nome no altar da Glória!

[...]

Charton só uma, que no mundo impera! (ASSIS, 1856, p. 4)

\section{A talvez primeira tradução}

Somente quatro anos depois, Machado de Assis voltaria às páginas do Diário do Rio de Janeiro e justamente com a primeira versão de sua tradução de "Maria Duplessis", em 15 de abril de 1860. Se se insistir em levar em conta a data, 31 de dezembro de 1855, em que Braga escreveu a sua, e a nota enviesada de Crisálidas, em que afirmou que "No dia aprazado apresentamos e confrontamos o nosso trabalho" (ASSIS, 1864, p. 170), não seria despropósito algum supor que, ao contrário de 1858, tal confronto teria sido mesmo no início de 1856, o que obviamente faria com que esta tradução fosse, na verdade, a primeira de Machado de Assis. No entanto, como há um hiato temporal entre elas, a única objeção a tal hipótese é que, a princípio, não há garantias de que a versão publicada em 1860 no Diário do Rio de Janeiro seja a mesma de 1856, mas, ao mesmo tempo, como se mostrará a seguir, existem no poema machadiano vários indícios, formais e textuais, que igualmente reforçam (e muito) essa possibilidade.

Em outras palavras, a versão de 1860 traz em si evidentes diálogos com as versões de Leonel de Alencar e de Gonçalves Braga. A despeito da também possibilidade de que, pelo mesmo hiato temporal, Machado de Assis possa ter tido acesso ao original em francês de Dumas Filho, continua sendo deveras intrigante que ele tenha traduzido, tanto na versão do Diário do Rio de Janeiro quanto na de Crisálidas, apenas dezesseis das dezessete estrofes da tradução em prosa de Leonel de Alencar e da, em verso, de Braga. E ainda com o detalhe adicional de que, assim como o poeta português, tenha mantido a mesma inversão das estrofes 7 e 8 da versão inicial de Alencar. 
Outro dado singular da tradução machadiana é a curiosa exclusão de uma estrofe, presente nas versões de Alencar e de Braga. Sintomaticamente, a estrofe de número 14 (17 no original francês) é revestida por uma mais que evidente carga de viés erótico, seja em Leonel de Alencar, "Recordas-te das noites em que ardente e amorosa torcias aos meus beijos teu corpo voluptuoso? - E fatigada encontravas o sono, consumida e trêmula na febre do gozo?" (ALENCAR, L. 1855b, p. 3), seja em Gonçalves Braga, "Recordas-te da noite em que meus beijos / Fugias com teu corpo voluptuoso, / E cansada de amor, já vinha o sono / Cerrar teus olhos, tão febris de gozo?" (BRAGA, 1856a, p. 3). A opção machadiana por tal exclusão talvez possa ser explicada ou em razão de eventuais pudores morais do poeta adolescente e que, inclusive, se refletirão em obras futuras, dado o seu recorrente comedimento no tratamento dessa matéria temática, ou, quem sabe, em razão de pura e simples decisão de natureza estética.

De toda maneira, ao também decidir manter a mesma estrutura formal da tradução de Gonçalves Braga, parece que, no fundo, Machado de Assis insistiu no trabalho inicial de metrificar a tradução de Alencar, reforçando o intento comum dos poetas de fazerem "uma tradução livre ou paráfrase destes versos de Alexandre Dumas Filho" (ASSIS, 1864, p. 170). Além disso, como o poema machadiano saiu no Diário do Rio de Janeiro em 15 de abril, ou seja, pouco mais de um mês depois da morte de Francisco Goncalves Braga em 10 de março de 1860, talvez possa ter sido o modo cifrado e silencioso que Machado de Assis encontrou para homenagear o "finado amigo", de quem, a essa altura da vida, já estava um tanto distante. ${ }^{9}$ Veja-se, por fim, a tradução de Machado de Assis, publicada no Diário do Rio de Janeiro com o título de "Maria Duplessis (A dama das camélias) - Imitação de Alexandre Dumas Filho":

Fiz promessa, dizendo-te que um dia

Eu iria pedir-te o meu perdão;

Era dever, ir abraçar primeiro

\footnotetext{
9 Em 25 de outubro de 1858, Machado de Assis publicou no Correio Mercantil o poema "Esperança (No álbum do Sr. F. G. Braga)", trata-se da última homenagem pública que fez ao "mestre" Gonçalves Braga. Depois dessa data, em 18 de setembro de 1859, na coluna Revista de teatros de $O$ Espelho, ao comentar a comédia Minha sobrinha e meu urso, ainda faria uma rápida alusão ao "amigo" que traduzira a peça do francês: "A tradução é ótima; o Sr. Gonçalves Braga, moço de talento e bom senso, sobretudo, que é o que falta a muitos talentos - merece por certo aplausos por esse trabalho" (ASSIS, 1858, p. 2; CORREIO MERCANTIL, 1855, p. 2; ASSIS, 1859b, p. 6-8).
} 
A minha doce e última afeição.

E quando ia apagar tanta saudade Encontrei já fechada a tua porta; Soube que uma recente sepultura Muda fechava a tua fronte morta.

Soube que após um longo sofrimento Agravara-se a tua enfermidade; Viva esperança que eu nutria ainda Despedaçou - cruel fatalidade!

$\mathrm{Vi}$, apertado de fatais lembranças, A escada que eu subia tão contente; $\mathrm{E}$ as paredes, herdeiras do passado, Que vêm falar dos mortos ao vivente.

Subi, e abri com lágrimas a porta, Que ambos abrimos a chorar um dia; E evoquei o fantasma da ventura Que outr'ora um céu de rosa nos abria.

Sentei-me à mesa onde contigo outr'ora, Em noites belas de verão - ceava. Desses amores plácidos e amenos Tudo ao meu triste coração falava.

Fui ao teu camarim e vi-o ainda Brilhar com o esplendor das mesmas cores; E pousei meu olhar nas porcelanas Onde morriam inda algumas flores.

Vi aberto o piano onde tocavas;

Tua morte o deixou mudo e vazio, Como deixa o arbusto sem folhagem Passando o vale - vaporoso estio!

Tornei a ver o teu sombrio quarto Onde estava a saudade de outros dias... Um raio iluminava o leito à sombra Onde, rosa de amor, já não dormias. 
As cortinas abri - que te guardavam

Da luz mortiça da manhã, querida,

Para que um raio depusesse um toque

De prazer - nessa fronte adormecida.

Era ali que, depois da meia noite,

Tanto amor nós sonhávamos outr'ora;

E onde até o raiar da madrugada

Ouvíamos bater - hora por hora!

Então olhavas tu a chama ativa

Correr ali no lar, como serpente;

É que o sono fugia de teus olhos

Onde já te queimava a febre ardente.

Lembras-te agora, nesse mundo novo,

Dos gozos desta vida em que passaste?

Ouves passar no túmulo em que dormes

A turba dos festins que acompanhaste?

A insônia, como um verme em flor que murcha;

De contínuo essas faces desbotava;

E pronta para amores e banquetes

Conviva e cortesã te preparava!

Hoje, Maria, entre virentes flores

Dormes - em doce e plácido abandono:

A tua alma acordou mais bela e pura

E Deus pagou-te o retardado sono!

Pobre mulher! em tua última hora

Só um homem tiveste à cabeceira;

$\mathrm{E}$ apenas dois amigos dos de outr'ora

Foram levar-te à cama derradeira! (ASSIS, 1860, p. 2)

A despeito da comprovada proximidade temporal da tradução de Gonçalves Braga com a tradução em prosa de Leonel de Alencar, Machado de Assis, partindo com toda certeza da segunda, produziu uma versão mais contida. Em breve juízo crítico sobre o poema, Jean-Michel Massa, comparando a tradução machadiana com o original francês, observou que ele "foi o poeta que se emocionou ao ler a descrição de Dumas, a partir da qual 
sua inspiração criou uma peça de tom novo. A cópia é mais comovente do que o original" (MASSA, 2008, p. 72). Mas, como o intuito aqui não é o de fazer valoração estética, ressalte-se que, do ponto de vista formal e seguindo de perto o amigo português, Machado de Assis, como já se disse, manteve o mesmo arranjo estrutural na sua tradução: quadras com versos decassilábicos, rimando apenas nos pares. Como, ao que tudo indica, confrontaram mesmo os trabalhos em 1856, é o caso de supor que não apenas discutiram sobre as respectivas versões como, sobretudo, acordaram entre si que tal forma seria a mais adequada.

De início, para comprovar que, além da tradução de Gonçalves Braga, a de Machado de Assis também partiu da versão em prosa de Leonel de Alencar, o cotejo dos dois últimos parágrafos desta com as duas últimas estrofes das traduções dos poetas pode ser um exercício algo esclarecedor. Pois ajudará a perceber que os poetas não apenas dialogaram entre si, como também se apropriaram, de modos distintos, de vários elementos da tradução de Leonel de Alencar. Na sequência, vejam-se os textos de Alencar, Braga e Machado:

E agora Maria tu gozas, entre as flores, sem temor de acordar, o repouso desejado; - Deus soprou tua alma emurchecida, e pagou-te de uma vez o sono retardado.

Pobre mulher! Em tua última hora, só um homem assistiu ao teu derradeiro momento. - E somente dois amigos de teus amigos de outrora, levaram ao cemitério o teu saimento. (ALENCAR, L., 1855b, p. 3)

E agora, Maria, entre mil rosas

$\mathrm{Tu}$ gozas do repouso desejado,

Sem temor de acordar, que Deus pagou-te

De uma vez o teu sono retardado.

Pobre mulher! Na extrema hora da vida

Um homem viu teu último momento,

Dois amigos d'amigos teus de outr'ora

Conduziram teu fúnebre saimento! (BRAGA, 1856a, p. 3) 
Hoje, Maria, entre virentes flores

Dormes - em doce e plácido abandono:

A tua alma acordou mais bela e pura

E Deus pagou-te o retardado sono!

Pobre mulher! em tua última hora

Só um homem tiveste à cabeceira;

E apenas dois amigos dos de outr'ora

Foram levar-te à cama derradeira! (ASSIS, 1860, p. 2)

Na primeira estrofe, além de usar "E agora, Maria", "sem temor de acordar" e "repouso desejado", Gonçalves Braga incorporou integralmente aos versos finais o seguinte trecho de Leonel de Alencar: "Deus [...] pagou-te de uma vez o sono retardado", organizando-o na sua versão como: "Deus pagou-te / De uma vez o teu sono retardado", ou seja, apenas acrescentou o pronome "teu" que não existia na tradução de Alencar. Por sua vez, Machado preferiu usar "Hoje, Maria," ao invés de "Agora, Maria" e um sintético "Dormes" a "repouso desejado", mas, do mesmo modo que o amigo português, suprimiu o "de uma vez" e inverteu a posição de "retardado" da mesma passagem de Alencar, readequando-a em seu poema para: "E Deus pagou-te o retardado sono".

Já na segunda estrofe, Braga incorporou à sua versão "Pobre mulher!", retirou o "só" de "só um homem" e, além de usar a palavra "saimento" no último verso da estrofe, praticamente repetiu a seguinte passagem de Alencar: "dois amigos de teus amigos de outrora", apenas invertendo a posição do pronome "teus" para: "Dois amigos d'amigos teus de outr'ora". Por sua conta, Machado de Assis não apenas reproduziu integralmente no primeiro verso "Pobre mulher! Em tua última hora" da tradução de Alencar, como também usou o mesmo trecho do folhetinista, que, após a supressão do segundo "amigos" e do pronome "teus", resultou em: "dois amigos dos de outr'ora" na sua tradução.

Em outras palavras, a partir dos pontuais exemplos e, ao mesmo tempo, sem deixar de registrar que muitas outras apropriações aconteceram, é possível afirmar que, além de discutirem as respectivas versões dos poemas entre si, seja pela mesma opção formal, seja pela reprodução de passagens idênticas da tradução de Alencar, o que Francisco Gonçalves Braga e Machado de Assis fizerem nas suas traduções não foi, a rigor da palavra, a 
tradução do original francês de Alexandre Dumas Filho, mas apenas, e pela última vez, o mero exercício literário de metrificar a tradução em prosa de Leonel de Alencar. O que, diga-se de passagem, insere-se no terreno salutar do aprendizado poético, sobretudo para os "infantes da poesia", que, por razões nem tão claras, aventuraram-se pelos caminhos escorregadios da própria literatura.

Em suma, se, a princípio, não se pode afirmar que "Maria Duplessis" é a primeira tradução de Machado de Assis apenas e tão somente por não ter sido publicada em 1856, agora, no entanto, sabe-se que o poema machadiano não partiu do original de Dumas Filho, sendo, na verdade, a tradução da tradução em prosa de Leonel de Alencar, o que, para o crítico, não deixa de ser um duplo ganho. Entretanto, o fato de Machado de Assis ter mantido intacta a incompletude de sua tradução deixa entrevisto no ar uma névoa de interrogações, aliás, bem a seu gosto, e que, a despeito do referido hiato temporal, não permite descartar a hipótese de "Maria Duplessis" ter sido sua primeira tradução.

Pois, como se mostrou, além de o poema estar ligado à versão de Leonel de Alencar, persistem nele, por um lado, os diálogos formais e textuais com a versão de Francisco Gonçalves Braga, com quem o poeta brasileiro afirmou ter cotejado o resultado poético, e, por outro, ainda existe um último dado simbólico, o de "Maria Duplessis", com pontuais diferenças, ter sido republicada em Crisálidas. Se, na carta posfácio, o próprio Machado de Assis escreveu que havia deixado de fora do volume os "filhos das primeiras incertezas" por não ter tido tempo de coligi-los (ASSIS, 1864, p. 163), e se, ao mesmo tempo, a tradução foi escrita (ou começou a ser) em 1856, por que então foi incluída no livro de estreia poética? Ou, ainda levando-se em conta a nota sobre o poema em Crisálidas, além de Machado ter omitido tanto a data da publicação da versão de Braga quanto a de sua primeira versão, ambas no Diário do Rio de Janeiro, a referência ao ano de 1858, como o momento em que decidiram fazer as respectivas traduções, assim como a informação de que a sua seria de 1859, não poderiam ser pensadas como providenciais cortinas de fumaça para tentar nuançar a influência literária de Francisco Gonçalves Braga e a própria história da tradução? No final das contas, diante da ausência de respostas conclusivas, mas igualmente na presença de indícios reveladores, para o crítico, a exemplo daquele defunto autor, fica "um pequeno saldo", que não é "derradeira negativa", mas, ao contrário, é a vaga certeza de que "Maria Duplessis" pode ter sido mesmo a 
primeira tradução de Machado de Assis. Ou, ao menos, fica a sensação de que, no limite, o percurso deste poema machadiano, se non è vero, è ben trovato.

Anexo 1

\begin{abstract}
M.D. ${ }^{10}$
Nous nous étions brouillé; et pourquoi?... Je l'ignore;

Pour rien! pour le soupçon d'un amour inconnu.

Et moi qui vous ai fuie! Aujourd'hui je déplore

De vous avoir quittée et d'être revenu.
\end{abstract}

Je vous avais écrit que je viendrais, Madame,

Pour chercher mon pardon, vous voir, à mon retour;

Car je croyais devoir, et du fond de mon âme,

Ma première visite à ce dernier amour.

Et quand mon âme accourt, depuis longtemps absente,

Votre fenêtre est close et votre seuil fermé,

Et voilà qu'on me dit qu'une tombe récente

Couvre à jamais le front que j'avais tant aimé.

On me dit froidement qu'après une agonie

Qui dura quatre mois, le mal fut le plus fort,

Et la fatalité jette avec ironie,

A mon espoir trop prompt, le mot de votre mort.

J'ai revu, me courbant sous mes lourdes pensées,

L'escalier bien connu, le seuil foulé souvent,

Et les murs qui, témoins des choses effacées,

Pour lui parler du mort, arrêtent le vivant!

Je montai, je rouvris, en pleurant cette porte,

10 Esta versão do poema de Alexandre Dumas Filho apresenta diferenças pontuais em relação à primeira, publicada nos Péchés de jeunesse (1847), tanto na pontuação quanto em alguns dos versos. Aqui, no entanto, tais variantes não foram explicitadas. As estrofes em negrito não foram traduzidas e as em itálico tiveram suas ordens invertidas na tradução de Leonel de Alencar. 
Que nous avions ouverte en pleurant tous les deux, Et, dans mes souvenirs, j'évoquai, chère morte, Le fantôme voilé de tous nos jours heureux.

Je m'assis à la table où, l'un auprès de l'autre, Nous revenions souper aux beaux soirs du printemps, Et de l'amour joyeux, qui fut jadis le nôtre, $\mathrm{J}$ 'entendais chaque objet parler en même temps.

Je vis le piano, dont mon oreille avide Vous écouta souvent éveiller le concert, Votre mort a laissé l'instrument froid et vide, Comme en partant l'été laisse l'arbre désert.

J'entrai dans le boudoir, cette oasis divine Qui nous réjouissait de ses mille couleurs; Je revis vos tableaux, vos grands vases de Chine, Où se mouraient encore quelques bouquets de fleurs!

J'ai retrouvé votre chambre, à la fois douce et sombre! Et là le souvenir veillait fort et sacré.

Un rayon éclairait le lit donnant dans l'ombre, Mais vous ne dormiez plus dans le lit éclairé!

Je m'assis à côté de la couche déserte, Triste à voir comme un nid l'hiver, au fond des bois, Et je rivais mes yeux à cette porte ouverte, Que vous avez franchie une dernière fois.

La chambre s'emplissait de chaleur odorante, Des souvenirs joyeux et pâles, j'entendais Le murmure alterné de l'horloge ignorante Qui sonnait autrefois l'heure que j'attendais!

Je rouvris les rideaux qui, faits de satin rose, E voilant le matin le soleil à demi, Permettaient seulement ce rayon qui dépose La joie et le réveil sur le front endormi.

Or, c'est là qu'autrefois, ma chère ombre envolée, Nous restions tous les deux lorsque venait minuit; Et depuis ce moment jusqu'à l'aube éveillée, 
Nous écoutions passer les heures de la nuit.

Alors vous regardiez, éclairée à sa flamme, Le feu comme un serpent, dans le foyer courir, Car le sommeil fuyait de vos yeux, et votre âme Souffrait déjà du mal qui vous a fait mourir.

Vous souvient-il encore, dans le monde où vous êtes, Des choses de la terre? - et sur les froids tombeaux Entendez-vous passer ce cortège de fêtes

Où vous vous épuisiez pour trouver le repos?

Vous souvient-il des nuits où, brûlante, amoureuse, Tordant sous les baisers votre corps éperdu, Vous trouviez consumée à cette ardeur fiévreuse, Dans vos sens fatigués, le sommeil attendu?

Ainsi qu'un ver rongeant une fleur qui se fane, L'incessante insomnie étiolant vos jours, Et c'est ce qui faisait de vous la courtisane Prompte à tous les plaisirs, prête à tous les amours.

Maintenant, vous avez parmi les fleurs, Marie, Sans crainte du réveil, le repos désiré; Le Seigneur a soufflé sur votre âme flétrie, Et payé d'un seul coup le sommeil arriéré.

Pauvre fille! on m'a dit qu'à votre heure dernière, Un seul homme était là pour vous fermer les yeux, Et que sur le chemin qui mène au cimetière, Vos amis d'autrefois étaient réduits à deux!

Eh bien! soyez bénis vous deux qui, tête nue, Méprisant les conseils de ce monde insolent, Avez jusques au bout, de la femme connue En vous donnant la main mené le convoi blanc!

Vous qui l'aviez aimée et qui l'avez suivie! Qui n'êtes pas de ceux qui, duc, marquis ou lord, Se faisant un orgueil d'entretenir sa vie, N'ont pas compris l'honneur d'accompagner sa mort! (DUMAS, 1855, p. 193-195) 


\section{Referências}

ALENCAR, José de. Ao correr da pena. Diário do Rio de Janeiro, Rio de Janeiro, $2^{\text {a }}$ Série, n. 2, 7 out. 1855a, p. 1.

. Ao correr da pena. Diário do Rio de Janeiro, Rio de Janeiro, $2^{\text {a }}$ Série, n. 16, 21 out. $1855 \mathrm{~b}, \mathrm{p} .1$.

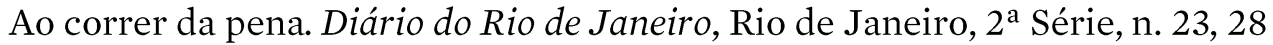
out 1855 c, p. 1.

Ao correr da pena. Diário do Rio de Janeiro, Rio de Janeiro, $2^{\text {a }}$ Série, n. 29, 04 nov. $1855 \mathrm{~d}, \mathrm{p} .1$.

. Ao correr da pena. Diário do Rio de Janeiro, Rio de Janeiro, 2a Série, n. 36, 11 nov. $1855 \mathrm{e}, \mathrm{p} .1$.

. Ao correr da pena. Diário do Rio de Janeiro, Rio de Janeiro, $2^{\text {a }}$ Série, n. 43, 18 nov. 1855 f, p. 1 .

Ao correr da pena. Diário do Rio de Janeiro, Rio de Janeiro, 2a Série, n. 50, 25 nov. 1855g, p. 1-2.

Ao correr da pena (folhetins inéditos). Estabelecimento de texto e introdução de Wilton José Marques. São Carlos: EDUFSCar, 2017.

ALENCAR, Leonel de. Revista: Livro do Domingo. Diário do Rio de Janeiro, Rio de Janeiro, $2^{\text {a }}$ Série, n. 77, 23 dez. 1855a, p. 1.

Revista: Livro do Domingo. Diário do Rio de Janeiro, Rio de Janeiro, $2^{\text {a }}$ Série, n. 83,30 dez. 1855 b, p. 2-3.

. Revista: Livro do Domingo. Diário do Rio de Janeiro, Rio de Janeiro, 2a Série, n. 76, 16 mar. 1860, p. 1.

ARARIPE JÚNIOR, Tristão de Alencar. José de Alencar: Perfil Literário. In:

Obra crítica de Araripe Júnior. Rio de Janeiro: Casa de Rui Barbosa, 1958. v. 3, p. 130-258.

ASSIS, Machado de. À Madame Arsène Charton Demeur. Diário do Rio de Janeiro, Rio de Janeiro, n. 38, 7 fev. 1856, p. 4.

Tradução de "A literatura durante a restauração", de Lamartine. Marmota Fluminense, Rio de Janeiro, n. 882, 15 set. 1857a, p. 1.

Tradução de "A literatura durante a restauração", de Lamartine. Marmota Fluminense, Rio de Janeiro, n. 883, 18 set. 1857b, p. 1.

Tradução de "A literatura durante a restauração", de Lamartine. Marmota Fluminense, Rio de Janeiro, n. 886, 29 set. 1857c, p. 3.

Tradução de "A literatura durante a restauração", de Lamartine. Marmota Fluminense, Rio de Janeiro, n. 888, 6 out. 1857d, p. 4.

Tradução de "A literatura durante a restauração", de Lamartine. A Marmota, Rio de Janeiro, n. 897, 6 nov. 1857e, p. 1-2. 
Tradução de "A literatura durante a restauração", de Lamartine. A Marmota, Rio de Janeiro, n. 899, 13 nov. 1857f, p. 3-4.

Tradução de "A literatura durante a restauração", de Lamartine. A Marmota, Rio de Janeiro, n. 905, 4 dez. 1857g, p. 2-3.

Esperança (No álbum do Sr. F. G. Braga). Correio Mercantil, Rio de Janeiro, n. 290,25 out. 1858 , p. 2.

A uma donzela árabe. O Paraíba, Petrópolis, n. 15, 20 jan. 1859a, p. 3.

Revista de teatros. $O$ Espelho, Rio de Janeiro, n. 3, 18 set. 1859b, p. 6-8.

Marie Duplessis (A dama das camélias) - Imitação de Alexandre Dumas

Filho. Diário do Rio de Janeiro, Rio de Janeiro, n. 21, 15 abril 1860, p. 2.

Crisálidas. Rio de Janeiro: Livraria de B. L. Garnier, 1864.

O velho Senado. In:

Obra completa. 3. ed. Rio de Janeiro: Nova

Aguilar, 1994. v. II, p. 636-644.

BRACARENSE, J. A Marmota, Rio de Janeiro, n. 1143, 16 mar. 1860.

BRAGA, Francisco Gonçalves. Ao Senhor J. M. M. de Assis (em resposta). Marmota Fluminense, Rio de Janeiro, n. 636, 14 out. 1855, p. 4.

Maria Duplessis (A transviada). Diário do Rio de Janeiro, Rio de Janeiro, n. 21, 21 jan. 1856a, p. 3.

Tentativas poéticas. Rio de Janeiro: Tipografia de Nicolau Lobo Viana \& Filhos, 1856b.

CORREIO MERCANTIL. Rio de Janeiro, n. 343, 14 dez. 1855.

DIÁRIO DO RIO DE JANEIRO. Rio de Janeiro, 2 ${ }^{\text {a }}$ Série, n. 70, 16 dez. 1855.

DIÁRIO DO RIO DE JANEIRO. Rio de Janeiro, n. 1, 25 mar. 1860a.

DIÁRIO DO RIO DE JANEIRO. Rio de Janeiro, 2a Série, n. 1, 6 out. 1860 b.

DUMAS, Alexandre. Marie Duplessis ou La Dame aux Camelias. Le Mousquetaire (Journal de M. Alexandre Dumas), Paris, n. 26, $1^{\circ}$ avr. 1855, Édition hebdomadaire, p. 193-195.

DUMAS FILS, Alexandre. Péchés de jeunesse. Paris: Fellens et Dufour Éditeurs, 1847.

MASSA, Jean-Michel. Machado de Assis tradutor. Trad. Oséias Silas Ferraz. Belo Horizonte: Crisálida, 2008.

A juventude de Machado de Assis, 1839-1870: ensaio de biografia intelectual. Trad. Marco Aurélio de Moura Matos. 2. ed. São Paulo: Editora Unesp, 2009.

SOUSA, J. Galante de. Bibliografia de Machado de Assis. Rio de Janeiro: INL, 1955.

VIANA FILHO, Luiz. A vida de José de Alencar. 2. ed. São Paulo; Salvador: Editora Unesp; EDUFBA, 2008. 
WILTON JOSÉ MARQUES é doutor em literatura brasileira pela Universidade de São Paulo. Professor de literatura brasileira e teoria literária do Departamento de Letras, do Programa de Pós-Graduação em Estudos de Literatura da Universidade Federal de São Carlos (UFSCar) e do Programa de Pós-Graduação em Estudos Literários da Universidade Estadual Paulista Júlio de Mesquita Filho (Unesp - Araraquara). Em 2011, recebeu o Prêmio Jabuti na categoria Crítica e Teoria Literária pelo livro Gonçalves Dias: o poeta na contramão (EDUFSCar, 2010). Posteriormente, publicou onze verbetes no Le dictionnaire universel des créatrices (Éditions des Femmes, 2013) e, mais recentemente, O poeta do lá (EDUFSCar, 2014), o poeta sem livro e a pietà indígena (Editora da Unicamp, 2015) e Ao correr da pena (folhetins inéditos), de José de Alencar (EDUFSCar: 2017). Atualmente, trabalha na pesquisa que trata do poema inédito "O grito do Ipiranga", de Machado de Assis. O presente artigo faz parte da pesquisa "Machado de Assis e as primeiras incertezas", financiada pelo CNPq. E-mail: will@ufscar.br

Recebido: 15.04.2018

Aprovado: 23.07.2018 